\title{
DE ALMANZOR A FELIPE II: LA INSCRIPCIÓN DEL PUENTE DE ALCÁNTARA DE TOLEDO (387/997-998) Y SU CURIOSA HISTORIA *
}

\author{
M. José RodRíGuEZ - Juan Antonio Souto \\ Universidad Complutense \\ A la memoria de Clara Delgado
}

\section{EN LA EsPaña de FeLIPE II}

El 1 de enero de 1567 entró en vigor en España una pragmática con medidas conducentes a la asimilación cultural de los moriscos, últimos musulmanes del país ${ }^{1}$. Tales medidas no eran las primeras ni serían las últimas en este sentido, pero sí que fueron particularmente duras, pues se referían muy en concreto a las características más propias de esas gentes: se les obligaba a abandonar sus vestidos peculiares, sus formas de celebrar las fiestas y los acontecimientos, sus prácticas higiénicas... y ante todo la lengua árabe, tanto hablada como escrita, en público y en privado ${ }^{2}$.

Fue sin duda en el marco de esas medidas, inscritas a su vez en una política de unificación general «hispana» ${ }^{3}$, que el rey Felipe II (1556-98) ordenó eliminar las inscripciones árabes de la ciudad de Toledo, lo que habría afectado a más de un centenar de ejemplares ${ }^{4}$. Junto con ello, el monarca mandó restituir anti-

* Este trabajo se enmarca en el proyecto «Epigrafía y construcción en al-Andalus omeya», subvencionado por la Fondation Max van Berchem y cuyos planteamientos básicos figuran en Souto, J. A., «Epigraphy and building in Umayyad al-Andalus: genesis and prospects for a research project», en Vermeulen, U., \& De Smet, S., eds., Philosophy and Arts in the Islamic World. Proceedings of the Eighteenth Congress of the UEAI, Lovaina, 1998, 303-24 (= «Epigraphy and building»). Agradecemos al doctor José Luis Miranda, ingeniero director de las obras de restauración del Puente de Alcántara de Toledo (1997-8), quien hizo posible nuestro acceso directo a sus inscripciones; a los doctores Federico Corriente y M. ${ }^{a}$ Jesús Viguera, que leyeron el borrador del presente artículo y nos aportaron valiosas sugerencias; y al doctor Luis Rodríguez, quien puso a nuestra disposición su magnífica biblioteca de temas toledanos.

${ }^{1}$ La bibliografía acerca de los moriscos es enorme. Véase la útil introducción de Harvey, L. P., «The Political, Social and Cultural History of the Moriscos», en Jayyusi, S. K., ed., The Legacy of Muslim Spain, Leiden, 1994, 201-34, con bibliografía de referencia entre las 233-4.

${ }^{2}$ Mármol Carvajal, L. de, Historia del rebelión y castigo de los moriscos de Granada, Málaga, 1600 (reed., Málaga, 1991), libro II, cap. VI. La ejecución de esta pragmática fue lo que condujo a la rebelión.

${ }^{3}$ Política que habría de culminar con la expulsión de los moriscos a comienzos del siglo XVII: «The quite sudden process whereby Spain's well-established Muslims were rejected and extruded as part of the larger process of the formation of Spain as a unitary nation-state will never be forgotten» (Harvey, op. cit., 201 -el subrayado es nuestro--).

${ }^{4}$ Toledo es una ciudad de fuerte substrato islámico. La obra de referencia al respecto sigue siendo la de Delgado Valero, C., Toledo islámico: ciudad, arte e historia, Toledo, 1987, a pesar de 
guas inscripciones latinas — versos del rey visigodo Wamba (672-80) — en lugares bien visibles de los más importantes accesos a la ciudad, donde también hizo colocar estatuas de sus santos patronos.

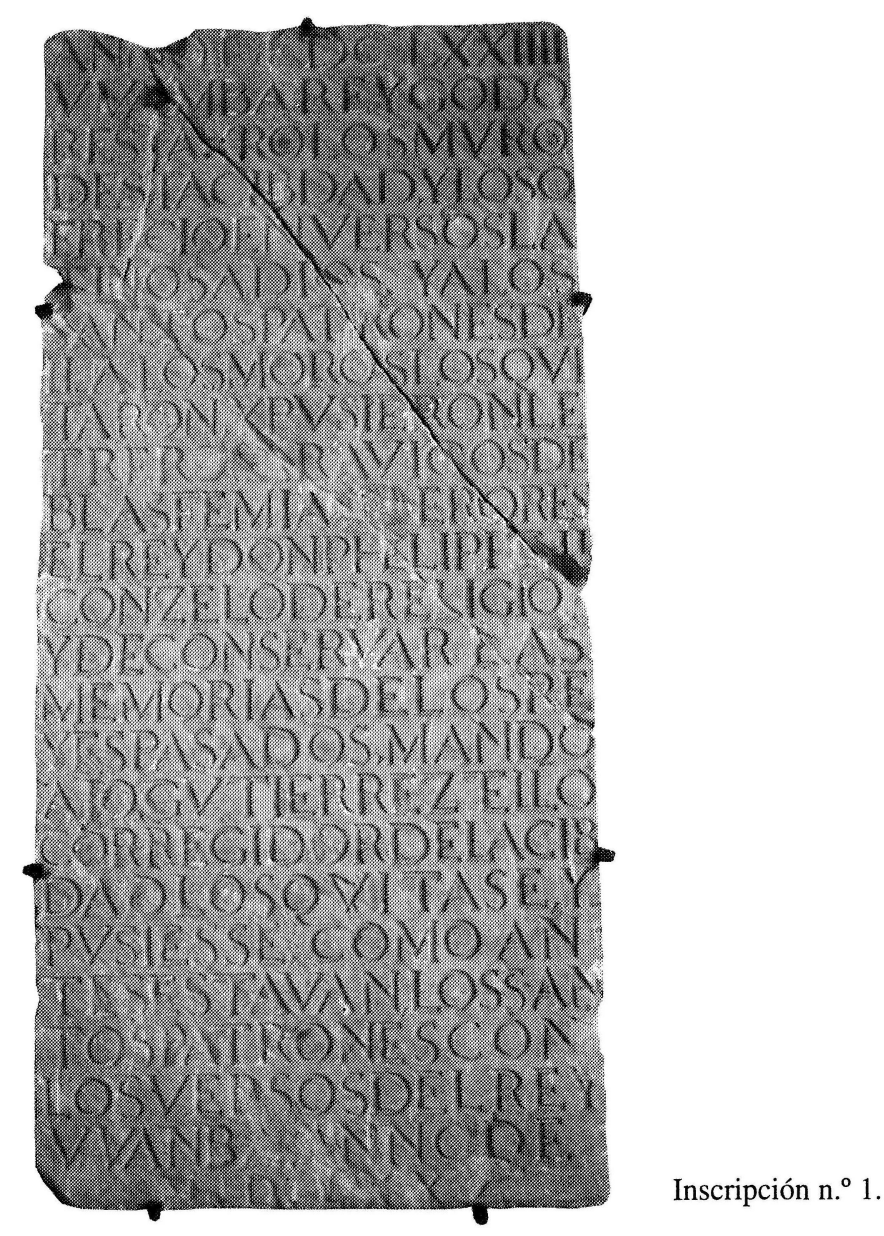

las abundantes publicaciones posteriores — véase, en este sentido, la reciente miscelánea de artículos contenida en el número monográfico Las ciudades del Andalus: Toledo, de la Revista del Instituto Egipcio de Estudios Islámicos en Madrid, XXX (1998)—. La eliminación de las inscripciones está recogida por numerosos autores: ver Delgado Valero, op. cit., 187, texto y notas, y LéviProvençal, E., Inscriptions arabes d'Espagne, Leiden, 1931, XI, texto y nota 2 (= Inscriptions arabes), donde se cita a Rodrigo Amador de los Ríos y a la fuente común de ambos, Pascual de Gayangos, quien a su vez se remite al P. Román de la Higuera. 
Estas órdenes, ejecutadas en 1575 por el corregidor Juan Gutiérrez Tello ${ }^{5}$, se plasmaron en epígrafes escritos en latín y castellano y con letras capitales humanísticas (inscripciones 1 y 2) ${ }^{6}$ que fueron puestos con las lápidas poéticas y las esculturas, o cerca de ellas. De esta forma se creó un programa figurativo renacentista que buscaba la exaltación del cuádruple carácter real, español, católico y clasicista de Felipe II ${ }^{7}$. Varias fueron las maneras, por demás indisociablemente entremezcladas, de conseguirlo:

1. Eliminación de los emblemas islámicos presentes en forma de inscripciones árabes ${ }^{8}$.

2. Invocación de la legitimidad real hispana, cuyas raíces se veían en la dinastía visigoda 9 .

3. Apelación al carácter cristiano - identificado con lo hispano- de los visigodos frente al Islam ${ }^{10}$.

4. Apelación al clasicismo mediante la invocación a los visigodos y la reproducción de los versos latinos de uno de sus reyes ${ }^{11}$.

5. Constancia documental en inscripciones de tipo clásico ${ }^{12}$.

${ }^{5}$ La del corregidor es una institución de origen bajomedieval. A grandes rasgos, era el representante y delegado político del monarca en una ciudad. Juan Gutiérrez Tello fue nombrado corregidor de Toledo por Felipe II en 1572. Murió en 1579 (Pedraza Ruiz, E., «Corregidores toledanos», Toletum, LXI, 8 (1977), 171-2).

${ }^{6}$ Las ediciones de las inscripciones (que publicamos en el «Apéndice») son nuestras. El lector advertirá que difieren, en mayor o menor grado, de las recogidas en su bibliografía (véase nuestra nota 14).

${ }^{7}$ Como introducción general a la figura y el tiempo de Felipe II, véanse las monografías colectivas de la serie Felipe II: un monarca y su época, Madrid, 1998, todas ellas con bibliografía orientativa.

${ }^{8}$ Véase la nota 13.

9 «España reivindicaba para sus monarcas y sus nobles esa progenie [visigoda] limpia de toda mezcla» (Gómez Moreno, Á., España y la Italia de los humanistas. Primeros ecos, Madrid, 1994, 280).

10 «Los españoles, por el espítitu de la Reconquista, veían en ellos [en los visigodos] un pasado glorioso, con un signo nacional y cristiano, que había que recuperar con una victoria definitiva frente al musulmán, al que siempre se consideró extranjero y enemigo de Cristo» (Gómez Moreno, op. cit., 280).

${ }^{11} \mathrm{Al}$ contrario de lo que ocurría en otras naciones europeas, que tenían a los godos como bárbaros aniquiladores de la cultura clásica, en España siempre se les tuvo como continuadores de ella, cuya ruptura vendría dada por la invasión musulmana de 711 .

${ }^{12}$ Las letras capitales humanísticas empleadas en estas lápidas de Felipe II «son el tipo clásico que mejor representa la restauración clasicista que se produce en el Renacimiento» (Castillo 


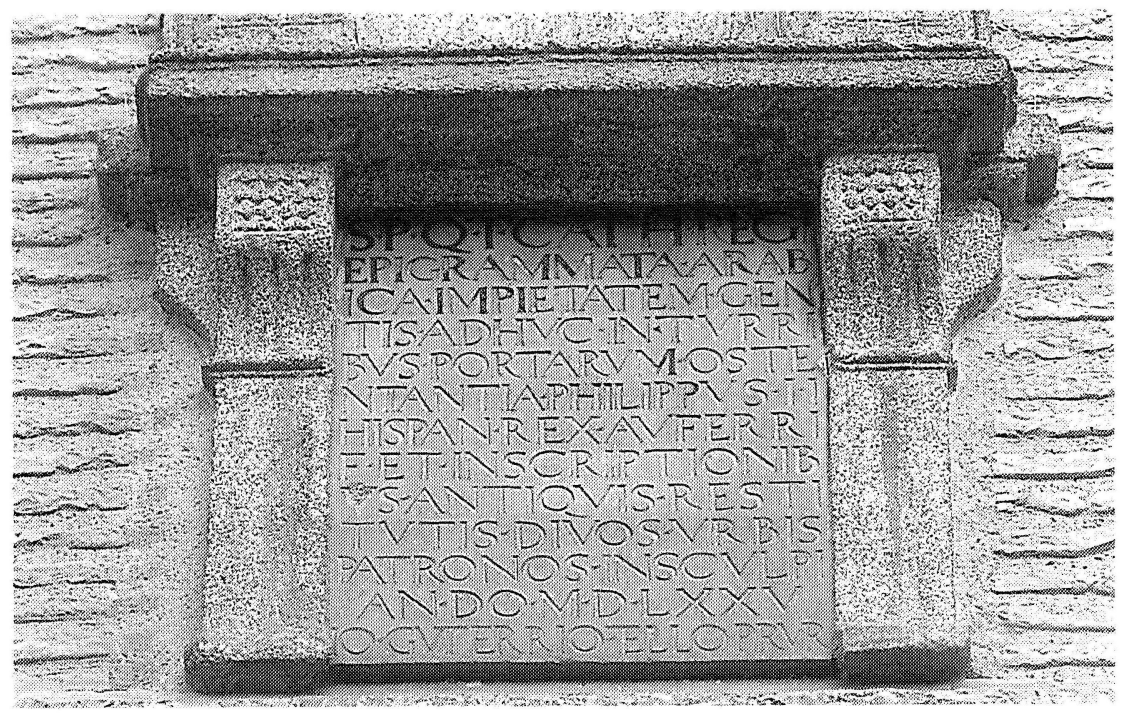

Inscripción $n .^{\circ} 2$.

Vemos que la palabra escrita, las lenguas empleadas, los tipos de letra y la propia escritura - su presencia y su eliminación - tenían importantes papeles en ese programa ${ }^{13}$.

La inscripción en castellano (inscripción n. ${ }^{\circ}$ 1) fue colocada en la hoy desaparecida Plaza de Armas, entre la Puerta de Alcántara y el puente homónimo. En cuanto a la latina, se hicieron al menos dos ejemplares con idéntico texto. Uno

Gómez, A., Escrituras y escribientes. Prácticas de la cultura escrita en una ciudad del Renacimiento, Las Palmas de Gran Canaria, 1997, 81, con bibliografía en nota 11). Destaquemos, sin embargo, que en las inscripciones 1,2 y 3 hay pervivencias medievales en forma de letras insertas $\left(>\mathrm{S}<\mathrm{en}>\mathrm{O}<\right.$ :.$^{\circ} 1$, línea 3$)$ o unidas $\left(>\mathrm{H}<\mathrm{y}>\mathrm{E}<: \mathrm{n}^{\circ}{ }^{\circ}\right.$, líneas 11 y $12 ;>\mathrm{T}<\mathrm{y}>\mathrm{E}<: \mathrm{n}^{\circ}{ }^{\circ}$, línea $17, \mathrm{n}^{\circ} 2$, línea 13, y n. $^{\circ} 3$, línea 5 ).

${ }^{13}$ La escritura es en él todo un «símbolo o marca de prestigio que está muy relacionado con el aspecto gráfico de las inscripciones, el cual adscribe éstas a referentes culturales distintos» (Castillo Gómez, op. cit., 79). Esto es válido para todo el público de la época, cristianos y musulmanes: hay que recordar la importancia de la lengua árabe y de la palabra escrita en el Islam, donde el valor emblemático de la escritura llega a ser independiente del mensaje que transmite, incluso del mismo hecho de que sea o no inteligible (Souto, J. A., «Marcas de cantero, graffiti y "signos mágicos" en el mundo islámico: panorámica general», Actas del V Coloquio Internacional de Gliptografía, I, Pontevedra, 1988, 473-4; respecto de las inscripciones oficiales: Blair, S., Islamic Inscriptions, Edimburgo, 1998, esp. 41-2). Es evidente que los encargados de elaborar la pragmática de 1567 eran muy conscientes de todo esto y obraron en consecuencia. Lo mismo cabe decir de los autores de este programa toledano de Felipe II. 
de ellos se conserva en la fachada interior del baluarte exterior de la Puerta Nueva de Bisagra, en Toledo; el otro, en la fachada exterior de la torre interior del Puente de Alcántara: es nuestra inscripción n. ${ }^{\circ}$ 2, la superior de un conjunto de tres ${ }^{14}$.

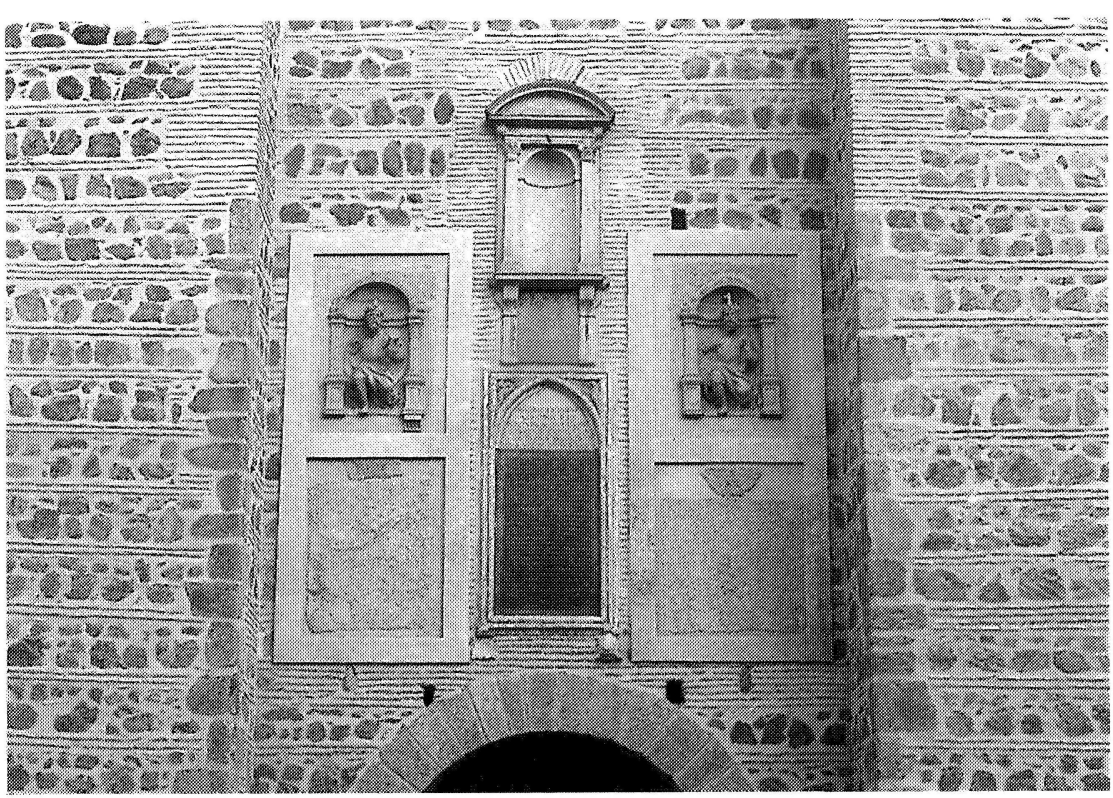

Fachada exterior de la torre interior del Puente de Alcántara de Toledo. En el centro y bajo el nicho vacío se observan, de arriba abajo, las inscripciones $n .^{\circ} 2,3$ y 4.

${ }^{14}$ Como muchos otros puentes, el llamado «de Alcántara», principal de Toledo hasta el siglo $\mathrm{xx}$, poseía y posee inscripciones de diversos tipos y cronologías. Casi toda la bibliografía dedicada a él las menciona, cuando no las edita: véase especialmente Torres Balbás, L., «Arte hispanomusulmán hasta la caída del califato de Córdoba», en Historia de España dirigida por Ramón Menéndez Pidal, V, reed., Madrid, 1982, $622-5$ (= «Arte hispanomusulmán»); Delgado Valero, op. cit., 184-92; Pavón Maldonado, B., Tratado de arquitectura hispanomusulmana. I. Agua, Madrid, 1990, 130-41; Malalana Ureña, A., «Puentes-fortaleza en el Tajo: el tramo Zorita de los Canes (Guadalajara - Castros (Cáceres)», Boletín de Arqueología Medieval, 4 (1990), 206-13; Vega Jimeno, M. de la, «Puentes romanos y de origen romano en la provincia de Toledo», Anales Toledanos, XXI (1994), 30-5, con bibliografía casi exhaustiva en pp. 34-5; y Aranda Alonso, F., \& Al, El sistema hidráulico romano de abastecimiento a Toledo, Toledo, 1997; 73 . Es de señalar que en el mismo año 1575 se aprobó que Juanelo Turriano emprendiese la construcción de un segundo ingenio, próximo a este puente, para subir agua del Tajo al Alcázar de Toledo. 


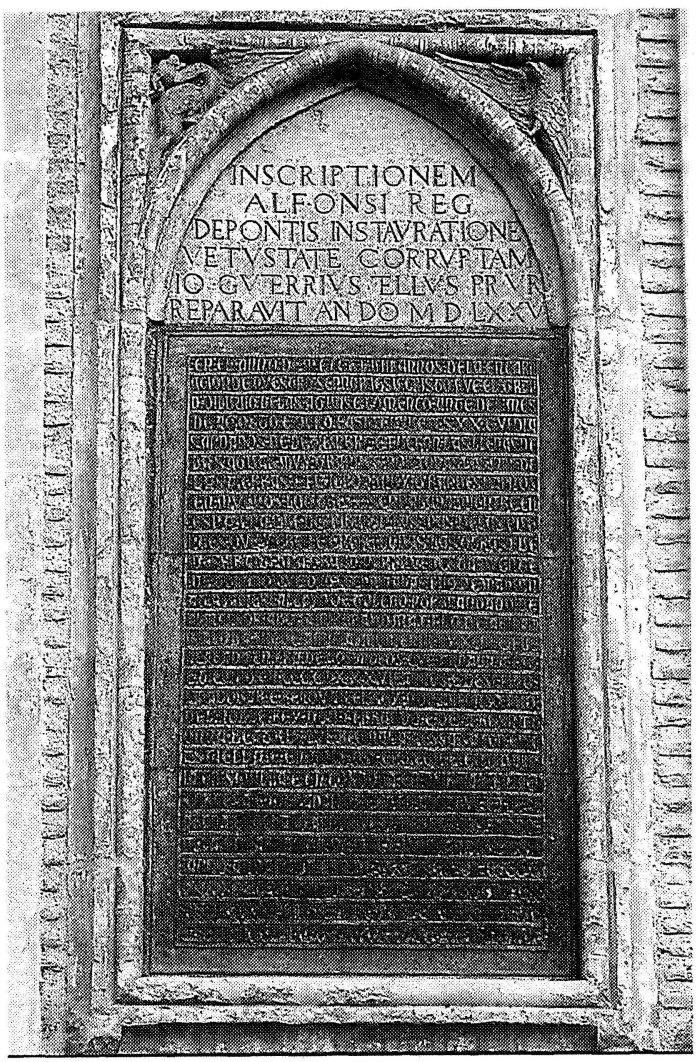

Inscripciones $n^{\circ} 3$ y 4 .

Bajo ese documento, una segunda inscripción en latín y capitales humanísticas (nuestra n. $^{\circ} 3$ ) introduce el siguiente capítulo de los hechos que nos interesan: Juan Gutiérrez Tello reparó (reparavit), debido a su mal estado, un epígrafe conmemorativo a nombre del rey Alfonso X de Castilla (1252-84). Se trata de la inscripción n. ${ }^{\circ}$ 4, fechada en 1259 y cuya naturaleza es doblemente «anticlásica», pues está escrita en lengua castellana y letras góticas ${ }^{15}$. Como vemos, esto no impidió que fuese aprovechada como parte del programa renacentista, pues al ser

${ }^{15}$ Parece claro, dado que sus rasgos gráficos son netamente del siglo XIII, que el reparavit que figura en la $n .^{\circ} 3$ significa «reparar» 0 «restaurar». Suponemos que lo que se hizo fue limpiarla o poco más. Francisco de Pisa, en la p. 22v de su Descripción de la Imperial Civdad de Toledo..., Toledo, 1605, se refiere a ella como «vna piedra antigua, que al presente està renouada, y dorada por Tello Corregidor». Sólo un buen estudio material podrá zanjar claramente esta cuestión. Pero sea lo que fuere lo que se hizo en 1575, el texto en sí del epígrafe no debió ser alterado. Agradecemos a la doctora Isabel Velázquez, del Departamento de Filología Latina de la Universidad Complutense, por sus precisiones en torno al significado del término reparavit en estos contextos y circunstancias. 
un epígrafe real era un emblema más de esa «cadena de legitimidad» cuyos primeros eslabones estaban en una dinastía precisamente de origen godo y cuya última encarnación era el propio rey Felipe II, biznieto de los Reyes Católicos. En cuanto a que estuviese escrita en una lengua «vulgar» - ya veremos las razones-, hay que señalar que si una de las bases sobre las que se cimentaron el Humanismo y el Renacimiento fue la recuperación del latín, otra fue la «clara voluntad de dignificar y, a través de esa vía, reivindicar las distintas lenguas vernáculas. [...] El culto a las lenguas nacionales, en compañía del mejor de los latines, contó también en Italia y en España con sus primeros testimonios» ${ }^{16}$. Lo que sí resulta llamativo es que, al obrar así, Juan Gutiérrez Tello, ese corregidor tan implacable con las inscripciones árabes como mimoso con las latinas, conservó y asimiló un epígrafe donde se transmitían restos de otro que, de haber sobrevivido hasta entonces, se hubiera perdido irremediablemente. Nos referimos al resumen castellano de la inscripción conmemorativa de una construcción, escrita originalmente en árabe y datada en el año 387/4 enero 997-2 enero 998.

2. LA INSCRIPCIÓN DE 387/997-8: TEXTUS RECEPTUS Y ENSAYO DE RESTITUCIÓN DEL ORIGINAL ÁRABE

Éste es el fragmento de la inscripción de 1259 (inscripción n. ${ }^{\circ}$ 4) que hace referencia a una construcción efectuada en 387/997-8:

[...]DESTA PVENTE DE TOLEDO QVE OVO FEChA hALAF FIIO DE MAhOMAT ALAMERI ALCAYD dE TOLEDO POR MANDADO DE ALMANÇOR ABOAAMIR MAhOMAT FIIO DE ABIhAMIR ALGUAZIL DE AMIR ALMOMENIN hYXEM E FUE ACABADA EN ERA DE LOS MOROS QUE ANDAUA A ESSE TIEMPO EN CCC E LXXXVII ANNOS [...]

Consideramos que este fragmento es un resumen en castellano de una inscripción constructiva omeya andalusí (ICOA) de carácter oficial. No creemos que se trate de una copia - traducción - literal, pues el modelo de las ICOA califales suele seguir un esquema relativamente rígido ${ }^{17}$ :

${ }^{16}$ Gómez Moreno, op. cit., 52. Sobre la cuestión lengua vulgar / lenguas clásicas en la España del Renacimiento, véase cap. VI, 109-20. Sobre la exaltación del castellano, 117 y ss.

${ }^{17}$ Llamamos «inscripciones constructivas» a todas aquellas que hacen referencia a cualquier aspecto de la construcción de un edificio -0 de parte de un edificio-, sus mecenas o sus artífices. Este esquema ideal —que no es invariable, sobre todo en el orden de los elementos - parte del análisis de las ICOA califales de carácter oficial y en forma de lápida incluidas en el catálogo pro- 
1. Basmala.

2. Orden de construcción, expresada con el verbo amara («ordenó») y la preposición $b i$-, que precede al

3. Nombre de acción de la construcción ('amal, binā', bunyān...).

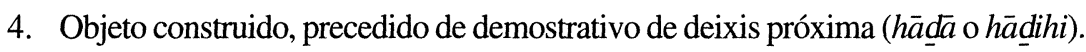

5. Cargo del sujeto de la orden.

6. Nombre del sujeto de la orden.

7. Frase propiciatoria, indispensable si el sujeto es el soberano. Como en este caso es su subordinado, la frase debiera ir dedicada al soberano, a quien por lo demás se nombraría como parte del sintagma de rección constitutivo del cargo (punto 5) ${ }^{18}$.

8. Testimonio de la conclusión de la construcción, expresado mediante el verbo tamma («se terminó»).

9. Referencia al auxilio divino, expresada generalmente bi- 'awni llāh («con el auxilio de Dios»).

10. Referencia a la dirección honorífica de la obra, introducida por la expresión 'alà yaday («bajo la dirección de»).

11. Expresión del cargo oficial del director honorífico de la obra.

12. Nombre de ese director.

13. Fecha.

14. Mención del auténtico director o autor de la obra.

visional del proyecto «Epigrafía y construcción en al-Andalus omeya» (véase nota *). En Inscriptions arabes, p. XVIII, figura uno muy similar. El desarrollo de estos esquemas puede verse en Blair, op. cit., esp. 29 y ss. Las inscripciones constructivas de carácter privado, así como las que aparecen sobre otros soportes - capiteles, por ejemplo-, introducen considerables variantes.

${ }^{18}$ Por lo que se produciría aquí una alteración de orden. Véase el apartado 3.2.2. 
He aquí de nuevo el fragmento toledano tras aplicar a sus elementos la numeración correspondiente a este esquema:

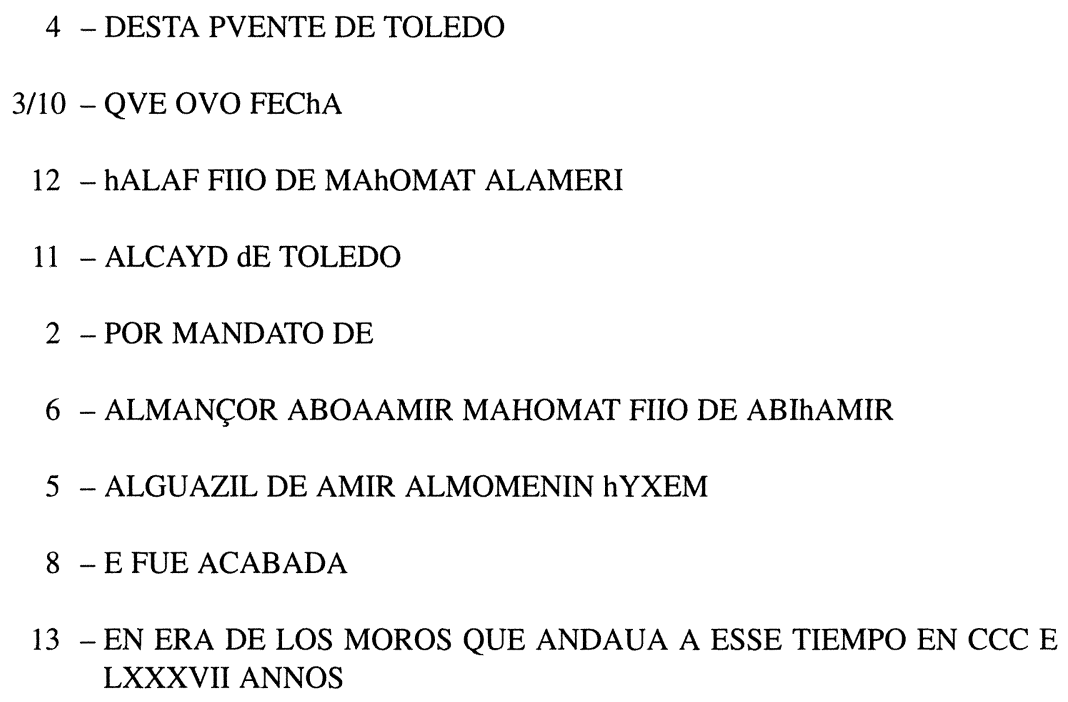

Si se considera el texto así numerado, se observará que presenta varias omisiones, varias alteraciones de orden, una intrusión y una posible confusión respecto del esquema «ideal» de las ICOA. Hay también una gran diferencia de estilo de escritura. Por todo ello creemos que no se trata de una copia-traducción fiel de una ICOA, sino de un resumen. Veamos punto por punto estos aspectos:

- Omisiones: se omiten los puntos 1, 7 y 9, es decir, las frases de tipo piadoso y «carácter islámico» que se debió considerar innecesario, y quizás hasta impropio, plasmar en el documento real alfonsino. Estas omisiones no impiden que la información sea transmitida íntegramente. Tampoco aparece el punto 14 , que no es, ni mucho menos, preceptivo.

- Alteraciones de orden: la más importante da como resultado la mención del director honorífico de la obra, un subordinado del soberano, antes que la de éste ${ }^{19}$ : en las ICOA el nombre del director jamás va delante del ordenante

\footnotetext{
${ }^{19}$ Sobre la cuestión del director honorífico y el director auténtico de las obras en al-Andalus omeya, así como sobre sus cargos y sus cometidos, véase Souto, J. A., «La práctica y la profesión del artista en el Islam: arquitectos y constructores en al-Andalus omeya «, Espacio, Tiempo y Forma, VII, 10 (1997), 11-34 (= «La práctica»); y Ocaña Jiménez, M., «Arquitectos y mano de
} 
de la obra, por evidentes razones de jerarquía. También figuran aquí los nombres antes que los cargos, al revés de la norma más extendida en las ICOA, lo que enlaza con las cuestiones relativas al estilo del documento castellano.

- Intrusión: al mencionar la obra, en el texto castellano aparece el nombre de la población donde se realizó («desta puente de Toledo»). En las ICOA el topónimo, cuando aparece, lo hace vinculado al cargo del director honorífico de la obra. Es por ello que «Toledo» consta dos veces en el texto castellano, siendo innecesaria la primera de ellas.

- Confusión: se confunde al director honorífico de la obra, el alcayd de Toledo, con el director o autor auténtico. Esto se debe a que se ha unido el concepto expresado con el nombre de acción (punto 3) al expresado con 'alà yaday, «bajo la dirección de» (punto 10) ${ }^{20}$. El director «auténtico», es decir, el autor, correspondería al punto 14 y no aparece mencionado, lo cual contribuyó a la confusión. En este caso concreto no habría que descartar, sin embargo, la posibilidad de que ambas direcciones coincidiesen en una sola persona, con lo que el propio texto original sería ya de por sí impreciso. Volveremos sobre ello en el apartado 3.2.3.

- Estilo: el fragmento castellano está redactado en un estilo narrativo historicista que pretende cierta «amenidad». Esta presentación de los datos de una ICOA como narración de hechos remotos a renglón seguido y sin ajustarse a fórmulas rígidas es el factor que conduce a las omisiones, alteraciones e intrusión mencionadas: se pretende integrar los hechos referidos por la antigua ICOA en el seno de un gran documento, la inscripción alfonsina, que es todo un relato coherente. Estamos convencidos de que no hubo intención de traducir total ni literalmente la inscripción árabe, sino de transmitir su información básica de la manera más clara e inteligible posible para el lector del siglo XIII integrándola en un documento de carácter cronístico, objetivo que

obra en la construcción de la gran mezquita de Occidente», Cuadernos de la Alhambra, 22 (1986), esp. 55-9 (= «Arquitectos y mano»). Recordemos que en pleno Renacimiento español el corregidor Gutiérrez Tello no pudo ser, evidentemente, el director auténtico del descrito programa filipino, sino su director honorífico en calidad de delegado del rey. Sobre la dirección de obras en la España de Felipe II y el papel del corregidor en ellas, véase González Tascón, I., «Organización y financiación de las obras públicas», en Felipe II. Los ingenios y las máquinas. Ingeniería y obras públicas en la época de Felipe II, Madrid, 1998, 41-71, esp. 67 y ss.

20 "Arquitectos y mano», passim, donde se advierte que la confusión de cargos y cometidos por parte de los estudiosos de las ICOA ha durado hasta nuestros días. Véase la nota anterior. 
estimamos bien logrado. Este carácter cronístico se deja ver también en la forma de expresar la fecha, «en era de los moros que andaua a esse tiempo». El resultado es un auténtico trabajo de interpretación muy bien hecho, no una rutinaria copia fruto de un simple traslado lingüístico. Es indudable que en él intervino un traductor profesional, sin duda un personaje bilingüe árabo-castellano, quizás mozárabe, judío o musulmán ${ }^{21}$. Y es asimismo evidente la labor conjunta entre él y un buen redactor, labor que desembocó en un extenso documento oficial que, sin dejar de serlo con todas sus consecuencias, roza también lo literario ${ }^{22}$. La razón de que la lengua empleada en la inscripción de 1259 fuese el castellano estriba en que «la usual diglosia medieval no se hallaba representada en Toledo [en época de Alfonso X] por el latín y el vernáculo, sino por éste y el árabe, con el latín relegado a un tercer lugar como lengua de cultura de segunda clase. Bajo tales condiciones de anómala triglosia, sólo el dialecto iberorrománico servía como koiné o medio de comunicación a las distintas comunidades de castellanos, mozárabes, mudéjares, judíos y francos» ${ }^{23}$.

Como conclusión podemos decir que la inscripción de 387/997-8 fue traducida al castellano e integrada en un documento - amplio, muy posterior cronológicamente y perteneciente a otra cultura bien distinta-consistente en una narración de hechos, lo que llevó a que su esquema se «diluyese», salvándose sin embargo la información básica que transmitía.

Hechas estas consideraciones, el texto de la inscripción de 387/997-8 podría reconstruirse asi ${ }^{24}$ :

${ }^{21}$ En este caso no podemos referirnos a lo que la historiografía actual ha dado en llamar «Escuela de Traductores de Toledo», sino a un auténtico trujamán dedicado a traducir textos con fines utilitarios inmediatos. Sobre la «Escuela», véase López Álvarez, A. M., \& $A l$, coords., $L a$ Escuela de Traductores de Toledo, Toledo, 1996, con bibliografía en pp. 75-80. Sobre el árabe hablado y escrito en el Toledo de la época, véase Ferrando Frutos, I., El dialecto andalusí de la Marca Media. Los documentos mozárabes toledanos de los siglos XII y XIII, Zaragoza, 1995.

${ }^{22}$ Esta forma de reparto del trabajo que suponemos entre «redactor oficial» y «ayudante-traductor» sí que sería semejante a la empleada para la traducción al latín de las grandes obras, en las que «el ayudante realizaría una versión oral romance del texto árabe, mientras que la misión del traductor sería realizar una versión latina, la única que - hasta la época de Alfonso X- se pondría por escrito» (Samsó, J., «Las traducciones toledanas en los siglos XII-XIII» en López Álvarez \& $A l$, op. cit., 18).

${ }^{23}$ Márquez Villanueva, F., «In Lingua Tholetana», en López Álvarez \& Al, op. cit., 31.

${ }^{24} \mathrm{La}$ numeración es la que hemos establecido para las ICOA (véase supra). Como criterios particulares de edición hemos de señalar que encerramos entre [ ] los fragmentos que no constan en el textus receptus; sólo representamos grafemas auxiliares en los casos estrictamente necesarios; y no puntuamos la $y \bar{a}$ ' final. ¿Vale la pena subrayar que nuestra reconstrucción es, por supuesto, hipotética? 

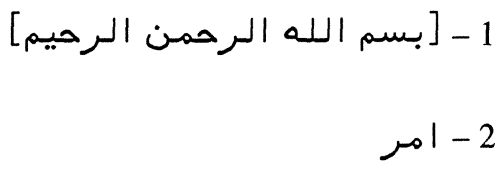

$$
3
$$

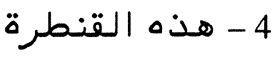

5 - وزير امير المؤمنين [المؤيد بالله] هشام

] - [اطال الله بقاءه]

6 - المنصور ابو عامر محمد بن ابن عامر

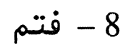

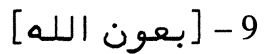

10

11 - قائد طليطلة

12 - خلف بن محمد العامرى

13 - فن سنة سبع وثما نين وثلاث مائة

1 - [En el nombre de Dios, el Clemente, el Misericordioso.]

2 - Ordenó

3 - la [re]construcción

4 - de este puente

5 - el wazìr del Emir de los Creyentes, [al-Mu'ayyad bi-llāh] Hišām 
7 - [-prolongue Dios su permanencia (en esta vida)- $]$,

6 - al-Manșūr Abū ‘Āmir Muḥammad b. Abī ‘Āmir.

8 - Y se terminó

9 - [con el auxilio de Dios]

10 - [bajo la dirección]

11 - del $q \bar{a}$ 'id de Toledo

12 - Jalaf b. Muḥammad al‘Āmirī

13 - en el año $387 / 4$ enero $997-2$ enero 998.

Se imponen las siguientes observaciones:

- 3: Bunyān, «[re]construcción». Parece obvio que el nombre de acción empleado fue un derivado del verbo banà, cuya dualidad semántica «construir» / «reconstruir», combinada con la cuestión de la dirección de la obra, jugó una mala pasada al traductor alfonsino, quien consignó ovo fecha al referirse a un puente que para 997-8 tenía ya siglos de antigüedad ${ }^{25}$. Lo más probable — dada su frecuencia- es que se emplease bunyān, como hemos consignado; no hay que descartar, sin embargo, los menos corrientes vocablos binā' e ibtinā', procedentes de la misma raíz.

- 4: Qantara, «puente». Hay tres razones que hacen indudable que el término empleado fuera éste y no otro: es el de uso más frecuente en al-Andalus ${ }^{26}$; es el empleado sistemáticamente por las fuentes árabes para referirse a este puente concreto ${ }^{27}$; y constituye hasta nuestros días su redundante nombre propio, «Puente de Alcántara».

- 5: Wazir. La palabra castellana alguazil (ortografiada actualmente alguacil) es claro arabismo derivado del andalusí alwazīr, a su vez del clásico wazì ${ }^{28}$.

${ }^{25}$ Sobre el verbo banà y su ambigüedad semántica, véase Souto, J. A., «Textos árabes relativos a la mezquita aljama de Zaragoza», Madrider Mitteilungen, 30 (1989), 394. Cf. bibliografía sobre el puente supra, nota 14.

${ }^{26}$ Corriente, F., A Dictionary of Andalusi Arabic, Leiden, 1997, raíz \{QNTR\} (= A Dictionary).

${ }^{27}$ Véase la bibliografía sobre el puente (nota 14).

${ }^{28}$ Corriente, F., «Hacia una revisión de los arabismos y otras voces con étimos del romance andalusí o lenguas medio-orientales en el Diccionario de la Real Academia Española», Boletín de 
Según Corominas, la forma alguazil aparece documentada por primera vez en castellano en $1115^{29}$.

- Amïr al-Mu'minin, «Emir de los Creyentes», está expresado mediante una simple transliteración, Amir Almomenin.

- Al-Mu'ayyad bi-llāh, «el Sostenido por Dios», es el laqab o sobrenombre honorífico del califa Hišām II. Aunque no aparece recogido en el textus receptus, es muy posible que figurase en la inscripción original, ya que tal ocurre en las dos únicas ICOA que se conservan con su nombre ${ }^{30}$.

- 6: Ațāla llāhu baqā'a-hu, «prolongue Dios su permanencia (en esta vida)». Esta expresión, al principio privativa de los soberanos ${ }^{31}$, aparece inscrita en al-Andalus desde época de 'Abd al-Raḥmān III. Sus primeros ejemplos con fecha expresa figuran sobre dos capiteles de 340/9 junio 951-28 mayo $952^{32}$. A partir de entonces será frecuente en las ICOA oficiales al menos hasta finales de 977 , fecha del último ejemplar conservado con ella ${ }^{33}$. No nos parece aventurado incluirla aquí, aunque no sabemos indefectiblemente si la inscripción original la tenía o no. En caso afirmativo, la alteración de orden introducida respecto del esquema «ideal» (7 antes que 6) debiera ser obligatoria, como se ha apuntado, máxime tratándose de un documento de Almanzor, quien cuidó de forma muy especial todo lo relativo a las formas externas de expresión de la legitimidad del califa Hišām y de su propia sumisión a ella ${ }^{34}$.

\footnotetext{
la Real Academia Española, LXXVI (enero-diciembre 1996), 89 (= «Hacia una revisión»). Téngase en cuenta que el significado actual del castellano alguacil no se corresponde con el del árabe wazìr, para el que hoy día se emplea «visir». Véase apartado 3.2.2.

${ }^{29}$ Corominas, J., Diccionario crítico y etimológico de la lengua castellana, Berna, 1954, s. $v$.

${ }^{30}$ Una de ellas fechada en rabì ' II 367/16 noviembre-14 diciembre 977: Inscriptions arabes, n. ${ }^{\circ}$ 30; la otra carece de fecha, aunque podría ser de ese mismo año o del anterior: Idem, n. 20 . Sobre este califa, véase nuestro apartado 3.2.1.

${ }^{31}$ Lo cual fue instituido por los califas 'Abbāsīes (Blair, op. cit., 38). Poco a poco esta exclusividad fue perdiendo vigor, ya que la fórmula en cuestión figura dedicada a 'Abd al-Malik, hijo de Almanzor, si bien en un objeto de uso personal, la conocida «pila de Marrakesh» (última publicación: Z[ozaya], J., en Dodds, J., ed., Al-Andalus. Las artes islámicas en España, Madrid-N. York, 1992, n. ${ }^{\circ} 43$. Lectura: Inscriptions arabes, n. ${ }^{\circ} 217$ ).

32 Ocaña Jiménez, M., «Capiteles fechados del siglo X», Al-Andalus, V (1940), 439-40 y lám. 7; y Gómez Moreno, M., «Capiteles árabes documentados», Al-Andalus, VI (1941), 424-5 y fig. 15.

${ }^{33}$ Inscriptions arabes, $\mathrm{n}^{\circ} 30$. Su uso se prolonga hasta época post-omeya, como puede comprobarse en esa misma obra, passim.

34 Véase apartado 3.2.2.
} 
- 9: Bi- ‘awni llāh, «con el auxilio de Dios». No es la única fórmula empleada al efecto en las ICOA, pero sí la más frecuente. El más antiguo ejemplar conservado con ella, procedente de Écija, data de muḥarram 318/3 febrero-2 marzo $930{ }^{35}$; el último, correspondiente a la mezquita toledada de Bāb al-Mardūm, está fechado en muharram 390/13 diciembre 99911 enero $1000^{36}$. Tampoco sabemos si se utilizó o no en el del Puente de Alcántara, pero su inclusión es una hipótesis con visos de verosimilitud.

- 10: 'Alà yaday, «bajo la dirección de». Ya hemos hablado de esta expresión, por lo que no insistiremos en torno a su significado. Aparece a lo largo de toda la epigrafía constructiva árabe y, naturalmente, de la omeya andalusí: desde la primera ICOA conocida, la fundacional de la primitiva mezquita aljama de Sevilla (214/11 marzo 829-27 febrero 830), hasta la última, la del citado oratorio de Toledo (13 diciembre 999-11 enero 1000). En aquella hace referencia a un director puramente honorífico, el gobernador ( $\left.q \bar{a} d_{i} i\right)$ de la ciudad; en ésta, a un director-autor auténtico, un constructor de oficio (bannāa') ${ }^{37}$.

- 11: $Q \bar{a} ’ i d$. El arabismo romance empleado en el textus receptus, alcayd (en castellano actual alcaide), es una simple transliteración del andalusí alqá$y i d$, clásico $q \bar{a}^{\prime} i d^{38}$. Corominas documenta por primera vez la voz alcaide en castellano en 1076.

\section{LA INSCRIPCIÓN DE 387/997-8: ALGUNOS COMENTARIOS HISTÓRICOS}

\subsection{Qué conmemoraba la inscripción}

Ignoramos a qué parte o partes del Puente de Alcántara se refería la inscripción de que tratamos. Es evidente que no constituye un documento de carácter

\footnotetext{
${ }^{35}$ Inscriptions arabes, n. $^{\circ}$ 29. Insistimos en lo de conservado, pues la expresión figuraría en la inscripción conmemorativa de la [re]construcción de la mezquita aljama de Madīnat Ilbīra, fechada en $\underline{d u} l$-qa' $d a$ del año 250/4 diciembre 864-2 enero 865, hoy perdida, y que conocemos a través de una crónica tardía (Inscriptions arabes, $\mathrm{n}^{\circ} 158$ bis). En el epígrafe de la Puerta de San Esteban de la aljama de Córdoba, del año 241/22 mayo 855-9 mayo 856, se encuentra el trasunto (Ccon la bendición de Dios y su auxilio» (Ocaña Jiménez, M., «Inscripciones árabes fundacionales de la mezquita-catedral de Córdoba», Cuadernos de Madinat al-Zahrā', 2, 198890, n. $\left.^{\circ} 1\right)$.

${ }^{36}$ Ocaña Jiménez, M., «La inscripción fundacional de la mezquita de Bīb al-Mardūm en Toledo», Al-Andalus, XIV (1949), 175-83; e idem, El cúfico hispano y su evolución, Madrid, 1970, n. ${ }^{\circ}$ XXVIII (=El cúfico). Véase nota siguiente.

37 «Epigraphy and building», apartado 3 , inscripciones 1 y 2 , respectivamente.

38 «Hacia una revisión», 77. Sobre sus significados, véase apartado 3.2.3 del presente trabajo.
} 
fundacional, puesto que el edificio en cuestión ya existía para la fecha, sino que conmemoraba obras de reconstrucción, reparación, ampliación o acondicionamiento más o menos importantes ${ }^{39}$. Junto con este objetivo inmediato hay otro no menos esencial, la doble exaltación de Almanzor como benefactor de la comunidad al mandar hacer obras en un puente y como fiel servidor del califa. La constancia por escrito del nombre y el cargo del gobernador también forma parte integrante de este programa propagandístico, no el último, que tenía como soporte este puente concreto.

\subsection{Los personajes documentados 40}

\subsubsection{Al-Mu'ayyad bi-llāh Hišām [II] b. al-Hakam}

Se trata del último califa (Amir al-Mu'minin) omeya andalusí que permaneció en el trono durante un tiempo prolongado. Su identificación no plantea problemas aquí ${ }^{41}$.

\subsubsection{Al-Manșūr Abū ‘Āmir Muḥammad b. Abī ‘Āmir}

Se trata del regente de al-Andalus desde la subida de Hišām II al califato en 976 hasta su propia muerte en $1002^{42}$. A lo largo de su carrera ostentó varios

\footnotetext{
${ }^{39}$ Ya se ha dicho algo al respecto al comentar la palabra bunyān. Sobre las fábricas islámicas del puente, véase la bibliografía citada en la nota 14 .

${ }^{40}$ Los consignamos por orden jerárquico.

${ }^{41}$ La obra básica sobre el califato de Hišãm II y la regencia de Almanzor —de quien nos ocupamos en el apartado siguiente- sigue siendo la de Lévi-Provençal, E., España musulmana hasta la caída del califato de Córdoba (711-1031 de J. C.), reed. Madrid, 1982, 402 y ss. (= España musulmana). Fuentes para la reconstrucción de su biografía: Uzquiza Bartolomé, A., «La familia Omeya en al-Andalus», en Marín, M., \& Zanón J., eds., Estudios onomásticos-biográficos de al-Andalus (familias andalusies), Madrid, 1992, n. ${ }^{\circ}$ 172. Las últimas consideraciones, que sepamos, son las de Bariani, L., «Sur le calife omeyade d'Espagne Hishām al-Mu'ayyad bi-llāh», comunicación presentada en el XIX Congreso de la UEAI, celebrado en Halle en septiembre de 1998. Los intercambios de información y opiniones mantenidos entonces con la autora nos fueron sumamente útiles.

${ }^{42}$ Véase la nota anterior. Las últimas publicaciones sobre este personaje son las de Guichard, P., «Al-Manșūr ou al-Manșūr bi-Llāh? Les laqab/s des Amirides d'après la numismatique et les documents officiels», Archéologie Islamique, 5 (1995), 47-53; Puente, C. de la, «La caracterización de Almanzor: entre la epopeya y la historia», en Ávila, M. L., \& Marín, M., eds., Biografía y género biográfico en el Occidente islámico. Estudios Onomástico-Biográficos de al-Andalus, VIII, Madrid, 1997, 367-402; y Bariani, L., «De las relaciones entre Șubḥ y Muhammad ibn Abī 'Āmir al-Manșūr con especial referencia a su «ruptura» (waḥša) en 386-388/996-998», Qurṭuba. Estudios Andalusies, 1 (1996), 39-57.
} 
títulos, entre ellos el de wazìr, que recibió en 976, y el de hāâyib, que recibió en 978, poco después del de $\underline{d} \bar{u}$ l-wizāratayn («dotado del doble visirato») ${ }^{43}$. «As early as 381/991-2, [...] al-Manșūr, the great häjib of the Umayyad dynasty, [...] had appointed his elder son, 'Abd al-Malik, to the post of hâjib and Sanchuelo [his younger son] himself to the rank of vizier. [...] He had given up the title of hajjib for himself, and contented himself with the throne-name of 'al-Manșūr'. A few years later, in 386/996-7, he adopted the title 'al-malik al-karim', ('The noble king')» ${ }^{44}$. La fuente de estos datos dice que abandonó (taraka) el título de hạâi ib, pero no que dejase el de wazìr, que por otra parte no tenía por qué ser unipersonal ${ }^{45}$. De ahí que en la inscripción toledana de 387/997-8 aparezca como wazìr y no como hāâyib del califa. Por lo demás, se trata del único epígrafe constructivo propiamente dicho conocido a nombre de Almanzor ${ }^{46}$, pues «su» otra inscripción se encuentra en un objeto mueble de carácter «privado», la llamada «pila de al-Zāhira», fechada en 377/3 mayo 987-20 abril 988. En ella figura, lógicamente, con el título de hầyib y la eulogia waffaqa-hu llāh («Dios le favorezca») ${ }^{47}$, que aunque es sabido se empleaba en sus escritos oficiales, no nos hemos atrevido a incluir en el texto toledano precisamente por estar en él el nombre del califa, que en tal caso debiera ser el destinatario único de este tipo de fórmulas. Sobre todo, como se ha dicho, teniendo en cuenta el alarde de sumisión formal de Almanzor hacia los Omeyas, de lo cual el epígrafe estudiado pretende ser testimonio público.

${ }^{43}$ Sobre el título de hāŷib y sus prerrogativas en este contexto, véase Meouak, M., «Histoire de la hiğăba et des hụğğa b en al-Andalus umayyade (2e/VIIIe-4e/Xe siècles)», Orientalia Suecana, XLIII-XLIV (1994-5), 155-64; sobre el de wazir, véase del mismo autor «Notes sur le vizirat et les vizires en al-Andalus à l'époque umayyade (milieu du II $/ \mathrm{VIII}^{\mathrm{e}}$-fin du IV $/ \mathrm{V}^{\mathrm{e}}$ siècles)», Studia Islamica, LXXVIII (1993), 181-90 (d̄u l-wizäratayn: 188-9).

${ }^{44}$ Wasserstein, D., The Caliphate in the West. An Islamic Political Institution in the Iberian Peninsula, Oxford, 1993, 116, donde se explican las razones de esta distribución de títulos. El sobrenombre «Sanchuelo» disgustaba a su posesor, ya que significaba «Cerdito»: cf. A Dictionary, raíz $\{$ ŠNČL $\}$.

${ }^{45}$ Al-Bayān al-Mugrib, II, ed. G. S. Colin \& E. Lévi-Provençal, reimp. Beirut, 1983, 293. Véase nuestra nota 43.

46 «Almanzor prohibió que se colocase en la parte añadida [por él a la mezquita aljama de Córdoba] ninguna inscripción conmemorativa mencionando su nombre y títulos; tampoco figuran los del califa nominalmente reinante. El hecho será cierto, pues, en contraste con la abundante epigrafía registrada en la ampliación, pocos años anterior, de al-Hakam II, ningún letrero histórico se ha encontrado en la debida a iniciativa del omnipotente ministro» («Arte hispanomusulmán», 573).

47 Última publicación de esta pila: Kubisch, N., «Ein Marmorbecken aus Madīnat al-Zahïra [sic] im Archäologischen Nationalmuseum in Madrid», Madrider Mitteilungen, 35 (1994), 398417, con bibliografía - hemos de señalar que las conversaciones en torno a esta pila mantenidas con la doctora Kubisch nos han sido de gran valía-. Lectura de la inscripción: Inscriptions arabes, n. $^{\circ} 216$, y El cúfico, n. ${ }^{\circ}$ XXVII. 


\subsubsection{Jalaf b. Muhammad al-'Āmirī}

Los únicos datos fidedignos acerca de este individuo son los contenidos en la inscripción que nos ocupa: Jalaf b. Muhammad al- 'Āmirī dirigió las obras del Puente de Alcántara en 387/997-8 siendo alcayd ( $q \bar{a}$ ’id) de Toledo.

Comencemos por analizar el onomástico: dadas las circunstancias en que aparece documentado, Jalaf b. Muhammad al-'Āmirī es claramente el nombre de un siervo o un mawlà de Muhammad al-'Āmirī, es decir, de Almanzor, de quien tomó su filiación al menos parcial (al-'Āmirī), si no completa (ibn Muhammad al-'Āmirī). Se trata, pues, de un personaje muy estrechamente vinculado al auténtico soberano de al-Andalus ${ }^{48}$.

¿Por qué Jalaf b. Muhammad al- 'Āmirī estuvo involucrado en las obras del puente? Hay dos explicaciones, complementarias entre sí: porque era un veterano constructor y porque era gobernador de Toledo en esos momentos.

Sobre su labor como constructor, la hipótesis planteable es tan arriesgada como sugerente: ¿se puede seguir la pista de Jalaf a lo largo de las obras de su época? Analicemos los datos disponibles: el más antiguo artista del que sabemos que se llamaba Jalaf y que estaba vinculado a los talleres omeyas andalusíes fue el autor de dos arquetas de marfil fechadas en Madīnat al-Zahrā' en 355/28 diciembre 96516 diciembre 966 y dedicadas a la hermana del califa al-Hakam II. Al final de sus inscripciones puede leerse «obra de Jalaf» ${ }^{49}$. A primera vista, no parece muy lógico que este Jalaf relacionado con la eboraria, evidentemente servidor de al-Hakam II, reaparezca 32 años más tarde como siervo o mawlà de Almanzor, si bien no podemos descartar del todo el que se trate de la misma persona.

Jalaf es también uno de los posibles nombres del responsable máximo de la confección de la citada pila de al-Madīna al-Zāhira (377/3 mayo 987-20 abril 988). Hoy día sólo es legible la primera letra del nombre del personaje que sigue a la expresión 'alà yaday: $\rightarrow$, puede ser $\hat{y} \imath m, h \bar{a}^{\prime}$ o jāa' ${ }^{50}$. Lèvi-Provençal dejó su edición en blanco ${ }^{51}$; Ocaña editó خلف a la vez que en el correspondiente comentario apuntó «... probablemente, Jayr» ${ }^{52}$. Ambas lecturas son restituciones

\footnotetext{
${ }^{48}$ Sabemos de otro caso con esta filiación y recogido epigráficamente: en la «arqueta de Leyre» (395/18 octubre 1004-7 octubre 1005) y en el «bote de Sayf al-Dawla» (1004-8), piezas de marfil dedicadas a 'Abd al-Malik, hijo de Almanzor, figura que se hicieron «bajo la dirección de al-fatà alkabir Zuhayr b. Muhammad al- 'Āmirī». En la arqueta se añade: «su esclavo (mamlük)». Referencia: $\mathrm{H}$ [olod], R., en Dodds, op. cit., n. ${ }^{\circ} 4$ y 5, respectivamente, con bibliografía. Lecturas: Inscriptions arabes, n. 204 (arqueta), corregida en El cúfico, n. ${ }^{\circ}$ XXIX; y 205 (bote), corregida en la ficha de Holod.

${ }^{49}$ Las arquetas se conservan en el monasterio de Fitero (Navarra) y en el Instituto de Valencia de Don Juan (Madrid). Lecturas: Inscriptions arabes, n. ${ }^{\circ} 197$ y 198, corregidas en El cúfico, n. ${ }^{\circ}$ XXII.

${ }^{50}$ Kubisch, op. cit., fig. 1 y lám. 50b. Téngase presente que las letras cúficas carecen de puntos diacríticos.

${ }^{51}$ Inscriptions arabes, $\mathrm{n} .{ }^{\circ} 216$.

52 El cúfico, n. ${ }^{\circ}$ XXVII. Jayr es uno de los autores de la «arqueta de Leyre». V. nota 46.
} 
hipotéticas. Y puesto que las palabras siguientes son al-fatà al-kabìr al- 'āmirì, este último vocablo no sería parte del antropónimo, sino un calificativo de alfatà, lo mismo que al-kabir: la lectura completa sería «el gran fatà 'àmirī» ${ }^{53}$, como en otros ejemplos. Sea como fuere, no es muy probable que el Jalaf que nos ocupa hubiera pasado de ese muy alto cargo a $q \bar{a}$ ' $i d$ a secas de una ciudad de provincias, por lo que esta pista se cierra aquí mismo.

Una tercera pista en busca del presunto Jalaf constructor lleva a la mezquita aljama de Córdoba: en la zona del oratorio correspondiente a la ampliación de Almanzor, cuyas obras comenzaron en 377/987-8, el mismo año de la pila de alMadīna al-Zāhira y diez antes que las del Puente de Toledo, hay tres fustes y un cimacio firmados por Jalaf (a secas) ${ }^{54}$ y cinco fustes firmados por Jalaf al'Āmirī ${ }^{55}$. Esta vez hay una gran coincidencia en el nombre y unos plazos cronológicos muy razonables. Por más que no podamos afirmar nada de manera categórica, encontramos sumamente tentadora la idea de que este último personaje, un hábil artista de la construcción y siervo o mawlà de Almanzor, como su onomástico atestigua, fuese diez años más tarde el encargado de dirigir una gran obra de ingeniería por orden de su señor.

Hablemos del cargo que poseía en 387/997-8: la palabra qā'id suele significar un empleo militar, pero su acepción como «alcalde» viene recogida por Alcalá en 1505: «alcalde $c$ [áid] al beléd... corregidor $c$ [áid] al belét» ${ }^{56}$. En la inscripción, el sintagma de relación qā'id al-balad («alcalde de la ciudad») está compuesto con el propio nombre del lugar, Tulaytula, Toledo. Las fuentes históricas permiten ver que el $q \bar{a}$ 'id en al-Andalus omeya «podía dirigir la administración de una región precisa» ${ }^{57}$. Entre los ejemplos disponibles pueden citarse algunos en las ciudades fronterizas de Zaragoza, Huesca y la propia Toledo ${ }^{58}$. A lo largo del siglo x la denominación de $q \bar{a}$ 'id sufrió una especie de «inflación», un desliza-

${ }^{53}$ Véanse las dos notas anteriores.

${ }^{54}$ Rodríguez, M. J. \& Souto, J. A., «De gliptografía omeya: signos lapidarios en la mezquita aljama de Córdoba. Situación e índice», Actes du Colloque International de Glyptographie de Palma, Braine-le-Château, 2000, 359-91 (fustes: E4, F4 y G9; cimacio: B20s).

55 Ídem, fustes B18, D17, F31, G27 y H31. Sobre la ampliación de Almanzor de la mezquita aljama de Córdoba, máxima expresión plástica de su ya aludida «sumisión» al califato omeya, véase Ewert, C. \& Wisshak, J. P., Forschungen zur almohadischen Moschee. Lieferung 1: Vorstufen, Maguncia, 1981, passim.

${ }^{56}$ Corriente, F., El léxico árabe andalusí según P. de Alcalá, Madrid, 1988, raíz \{qw/yd\}. Véase también Dictionary, raíz \{QWD\}. Obsérvese el uso de «corregidor» por este autor renacentista. Véase nuestra nota 5.

${ }^{57}$ Meouak, M., «Hiérarchie des fonctions militaires et corps d'armée en al-Andalus umayyade (II $/ \mathrm{VIII}^{\mathrm{e}} \mathrm{IV}^{\mathrm{e}} / \mathrm{X}^{\mathrm{e}}$ siècles): nomenclature et essai d'interprétation», Al-Qantara, XIV (1993), 378. Sobre el $q \bar{a}$ 'id: 375-80 (= «Hiérarchie des fonctions»).

58 Souto, J. A., «Cronología y gobernadores de Zaragoza omeya», A la Profesora Emérita María Luisa Ledesma Rubio en Homenaje académico, Zaragoza, 1993, 843-57; Ídem, «Cronología 
miento hacia la simple noción de título o dignidad ${ }^{59}$. De todo ello se colige que Jalaf b. Muhammad al- 'Āmirī podría haber haber sido gobernador de Toledo ${ }^{60}$.

¿Cuál fue entonces el papel real de Jalaf en las obras del Puente de Alcántara? Evidentemente, no lo sabemos. El textus receptus habla de la puente que ovo fecha Halaf..., pero no nos parece admisible traducir banà Jalaf, como ya hemos indicado, sino que este nombre aparecería tras 'alà yaday, «bajo la dirección de». De suponer que Jalaf era un constructor - y sólo un constructor - que llegó a lo más alto de su carrera como tal, sería posible que Almanzor lo enviase a Toledo con el fin exclusivo de dirigir las obras del puente en calidad de $q \bar{a}$ 'id en tanto autoridad de carácter militar acorde con el tipo de edificio donde iba a trabajar ${ }^{61}$. Habría entonces que pensar en una «doble dirección»: real, por cuanto constructor, y honorífica por cuanto $q \bar{a}$ ' $i d$. De suponer que no era un constructor de profesión ni tenía nada que ver con ese Jalaf al- 'Āmirī de Córdoba —o, al menos, que no era el mismo-, entonces debía tratarse simplemente del $q \bar{a}$ ' $i d$ (gobernador) de Toledo, y su dirección de las obras del puente sería tan sólo honorífica, haciendo las veces de representante del soberano. No es el único caso de un «qā'id director de obras» documentado epigráficamente en al-Andalus omeya: otro es Muḥammad b. Rumāhis, quien dirigiría - lo más probable es que sólo honoríficamente- obras de construcción en Almería en rabī' II 340-9/6 septiembre 951-28 junio $960^{62}$. El tercero era a la vez mawlà y $q \bar{a}$ ' $i d$ del califa alHakam II: Maysūr b. al-Ḥakam, bajo cuya dirección ('alà yaday) se [re]construyó un burŷ emplazado en el solar de la actual fortaleza de Baños de la Encina (Jaén) en ramadán $357 / 31$ julio - 29 agosto $968{ }^{63}$. En todo caso, cabe sumar ambas posibilidades: Jalaf $b$. Muhammad al- 'Āmirī pudo haber sido un maestro constructor que hizo carrera política y llegó a ejercer como qā' $i d$ de Toledo, car-

y gobernadores de Huesca omeya», Homenaje al Profesor José María Fórneas Besteiro, II, Granada, 1995, 857-65; y Delgado Valero, op. cit., 19 y ss.

59 «Hiérarchie des fonctions», 379-80. Vemos que el significado actual de la palabra castellana alcaide no se corresponde totalmente con su acepción medieval.

${ }^{60}$ Las fuentes sólo transmiten noticias acerca de un gobernador de Toledo durante la época 'ámirì: se trata de 'Abd Allāh b. 'Abd al-'Azīz, apodado «Piedra Seca», que aparece documentado por primera vez a comienzos de $371 / 7$ julio $981-25$ junio 982 y por última en $379 / 11$ abril $989-30$ marzo 990, es decir, antes de los hechos que nos ocupan. Véase principalmente España musulmana, 415-417; Viguera, M. J., Aragón musulmán, Zaragoza, 1988, 163-4; y Delgado Valero, op. cit., 35. Esta parquedad de datos al respecto es propia de la época de la regencia de Almanzor.

${ }^{61}$ Recuérdese el carácter militar de los puentes, que en ocasiones llegan a constituir auténticas fortalezas. El de Alcántara es un claro ejemplo.

${ }^{62}$ Ocaña Jiménez, M., Repertorio de inscripciones árabes de Almería, Madrid-Granada, 1964, n. ${ }^{\circ}$, y El cúfico n. ${ }^{\circ} 15$. En estos momentos la inscripción está siendo revisada por nuestro colega el doctor Jorge Lirola, de la Universidad de Almería, a quien debemos nuevos datos y observaciones.

${ }^{63}$ La última publicación de esta inscripción es la de Zozaya, J., en Salvatierra Cuenca, V., dir., El zoco. Vida económica y artes tradicionales en al-Andalus y Marruecos, Barcelona-Madrid, 1995, n. ${ }^{\circ} 19$. Advertimos que el texto se refiere a esta inscripción, pero la fotografía corresponde a otra. Azuar Ruiz, R., 
go que poseería cuando se hicieron obras en el Puente de Alcántara, de cuya dirección, honorífica o real o ambas a la vez, se habría encargado.

\section{OBSERVACIONES FINALES}

Si hoy sabemos algo de la inscripción de 387/997-8 es gracias a su resumen castellano, embebido en una lápida del rey Alfonso X. Surgen dos preguntas que son casi un guiño: ¿Fue consciente el corregidor Gutiérrez Tello de que al conservar el «legítimamente real e hispano» epígrafe de 1259 dejaba a la vez plasmado un emblema de la legitimidad de los califas Omeyas andalusíes y del usurpador Almanzor? ¿Mediría acaso las últimas consecuencias de lo que en verdad hizo? Nuestra respuesta es «no». Es más, ni siquiera creemos que aquel atareado y ubicuo corregidor conociese el texto en sí de la inscripción alfonsina, de cuyo contenido general tan sólo se le informaría para que, en su calidad de director honorífico de obras públicas, otorgara el visto bueno al programa de exaltación y diese lugar a que su nombre fuese escrito en piedra junto con el de su soberano.

Dos hechos semejantes se repitieron en el mismo escenario con casi seiscientos años de intervalo. La intención del segundo hubiera sido borrar hasta el último eco del primero, pero, cosas de la Historia, resultó burlado. Toda una metáfora de la vanidad del poder terrenal, de Almanzor a Felipe II.

\section{RESUMEN}

Este artículo trata de una inscripción constructiva omeya andalusí del año 387/4 enero 997-2 enero 998, hoy perdida, pero transmitida a través de un resumen castellano incluido en una lápida de 1259 «reparada» en 1575 . Se intenta la restitución del texto árabe original y se estudian los hechos y los personajes documentados.

\section{ABSTRACT}

This paper studies an Umayyad Andalusi foundation inscription, dated 387/4 January 997-2 January 998, which is no longer extant but has been transmited in a summary in Castilian on a tablet dated 1259 and repaired in 1575. An attempt is made to deduce the original Arabic text, and the documented facts and persons are discussed.

\& Al., «El falso despiece de sillería en las fortificaciones de tapial de época almohade en al-Andalus», Estudios de Historia y de Arqueología Medievales, XI (1996), 251, opinan - a nuestro juicio, acertadamente- que la actual fortaleza es de época almohade y que la lápida conmemora un edificio anterior. 


\section{APÉNDICE: CATÁLOGO DE INSCRIPCIONES}

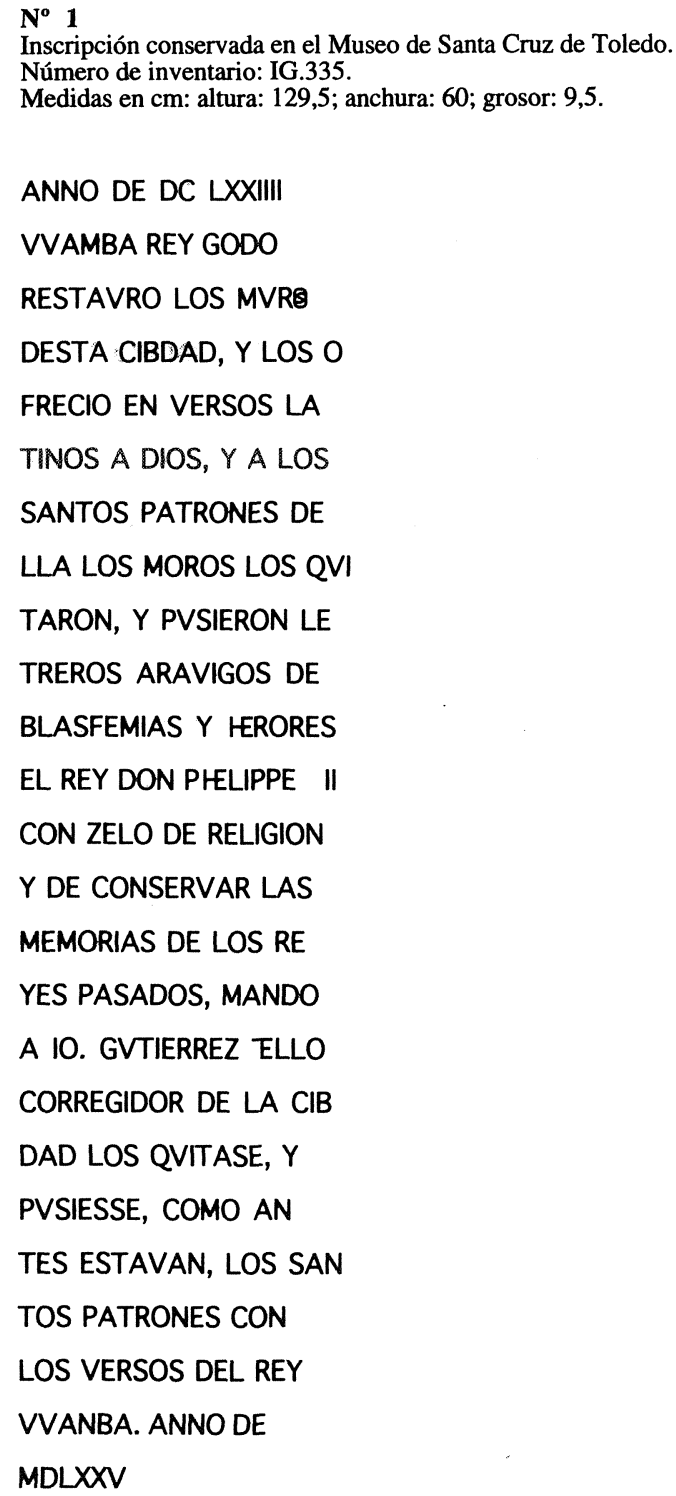


No 2

Medidas en cm: altura: 75; anchura: 59.

S. P. Q. T. CATH. REGI

EPIGRAMMATA. ARAB

ICA. IMPIETATEM. GEN

TIS. ADHVC. IN. TURRI

BUS. PORTARVM. OSTE

NTANTIA. PHILIPPVS. I.I

HISPAN. REX. AVFERRI

F. ET. INSCRIPTIONIB

VS. ANTIQVIS. RESTI

TVTIS. DIVOS. VRBIS

PATRONOS. INSCVLPI

AN.DO.M.D.LXXV

IO. GVERRIO. ELLO. PR. VR 


\begin{abstract}
$\mathbf{N}^{0} 3$
INSCRIPTIONEM

ALFONSI REG

DEPONTIS INSTAVRATIONE

VETVSTATE CORRVPTAM

IO GVERRIVS ELLVS PR VR

REPARAVIT AN DO M D LXXV
\end{abstract}

Lápida ojival. Medidas en cm: altura: 61,5; anchura de la base: 90 . 


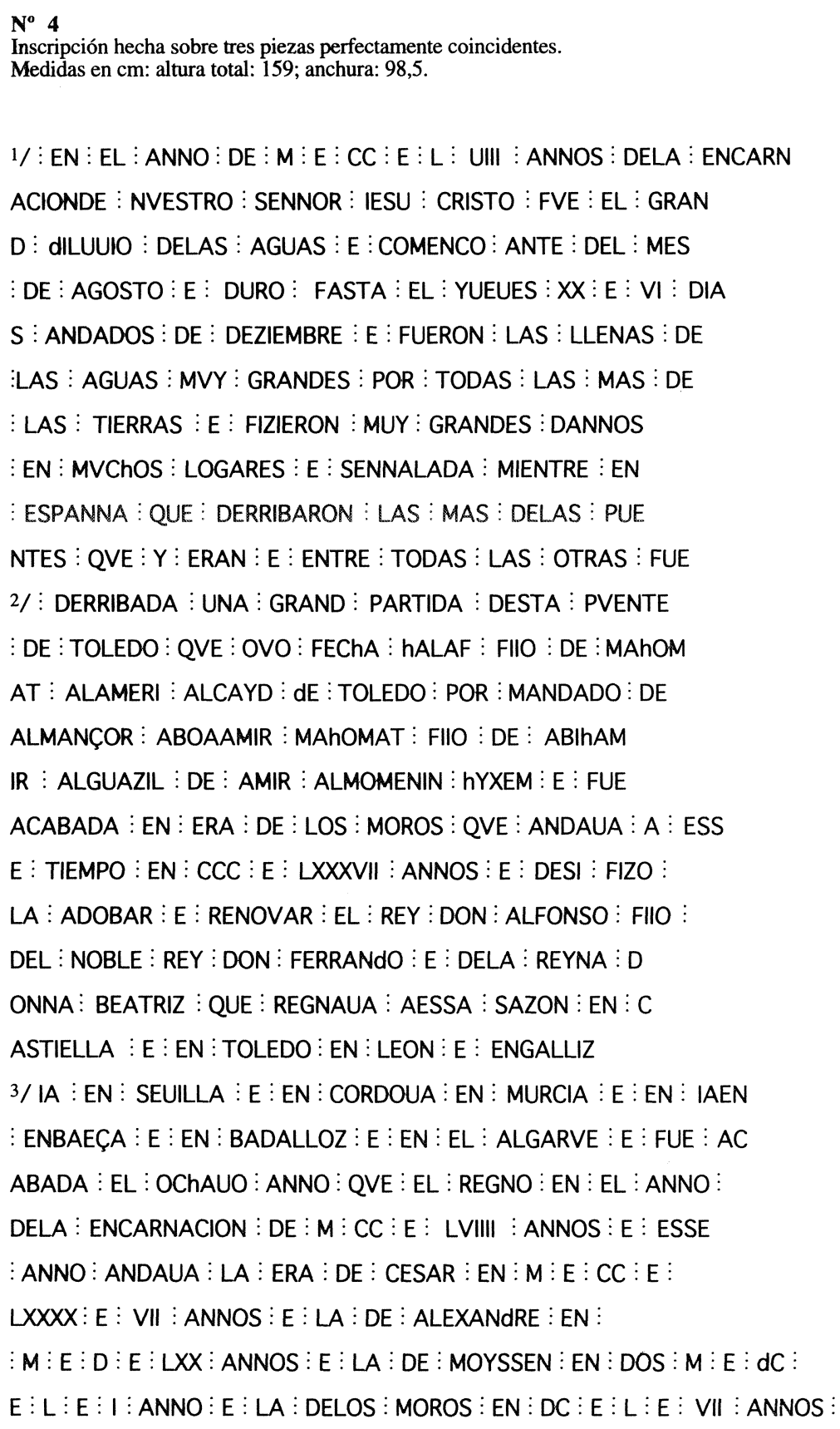

